\title{
MEDIDAS, ESTRATEGIAS Y ETAPAS DE LA RELEGACIÓN DURANTE LA DICTADURA DE PINOCHET COMO MECANISMO DE CONTROL Y DISCIPLINAMIENTO SOCIAL, 1973-1986
}

\author{
Measures, strategies and stages of relegation during Pinochet military regime \\ as a control mechanism and social discipline, 1973-1986
}

Javier González Alarcón*

\section{Resumen}

El siguiente artículo pretende analizar la relegación como un mecanismo de control y disciplinamiento social. El interés por este tema se basa en los escasos estudios que existen sobre la temática en el campo de la disciplina histórica y fundamentalmente para poder ampliar el conocimiento de los dispositivos de represión utilizados en el período estudiado. Para lo cual se procedió a identificar las medidas, estrategias y etapas que cumplió este dispositivo durante la dictadura de Pinochet. Poniendo particular énfasis en las dos etapas de relegación que se gestaron, primero entre 1973-1979, y segundo entre 1980-1986; los procedimientos de detención de los afectados; qué sujetos y lugares fueron relegados; el trato de los detenidos, desde su detención hasta su lugar de relegación; y algunos casos de relegación durante la dictadura cívico-militar. Para tal efecto se trabajó con los archivos de la Vicaría de la Solidaridad, FASIC, prensa de la época y testimonios que giran en torno al tema de estudio.

$$
<\text { Relegación }><\text { Control Social }><\text { Régimen Militar }>
$$

\begin{abstract}
The article pretends to analyze relegation as a control mechanism and social discipline. The interest on this subject is based on the limited studies that exist about this thematic in the field of historic discipline, and mainly to increase the knowledge on the repression devices used in the period studied. For this purpose, measures, strategies and stages that this device fulfilled during the military government were identified. Focusing on the two relegation stages that existed, first between 1973-1979 and second between 1980-1986, the arrests procedures of the affected, the individual and places they were relegated to, and some cases of relegation during civic-military dictatorship. For that matter, the work was done along with Vicaría de la Solidaridad files, FASIC, press of the time, and testimonies that concentrate on the topic of were studied.
\end{abstract}

$<$ Relegation $><$ Social Control $><$ Military regime $>$

Recibido: 7/05/2018 //Aceptado: 15/07/2018

\footnotetext{
* Licenciado en Historia por la Universidad Nacional Andrés Bello (Chile), Magíster en Historia por la Universidad de Concepción (Chile), jgonzalezalarcon1@gmail.com
} 
González Alarcón. Medidas, estrategias y etapas de la relegación durante la dictadura de Pinochet como mecanismo...

\section{Introducción}

La historiografía nacional ha mantenido una deuda importante con el estudio de la relegación en el transcurso de su historia, si bien, es un método de represión utilizado con frecuencia en cada una de las dictaduras nacionales y por algunos gobiernos elegidos democráticamente, como por ejemplo el de Gabriel González Videla, que mediante una ley excluyó al Partido Comunista chileno y muchos de sus militantes fueron relegados a Pisagua, los investigadores hasta la fecha han puesto énfasis en las desapariciones y los exilios, dejando de lado la importancia que mantuvo este mecanismo a lo largo de la historia nacional. Por consiguiente, cabe señalar que en la producción historiográfica, la relegación sólo ha ocupado algunas cuantas líneas en los estudios sobre represión ${ }^{1}$.

De esta forma, y de acuerdo al contexto estudiado, podemos inferir que desde el momento mismo en que se produjo el golpe de Estado, se inició un proceso ininterrumpido de graves violaciones a los derechos humanos con resultados de muerte y desapariciones (Acuña, 2015: 7). Durante los primeros años se acondicionaron regimientos, estadios, cuarteles, cárceles, Comisarías, retenes de Carabineros y algunas embarcaciones como por ejemplo, los Buques "Lebu", "Maipo" y el Buque Escuela "Esmeralda", para recibir a los detenidos. La Junta, convencida de la urgencia de una purificación ideológica nacional, creyó que era imprescindible un combate a fondo contra los partidos de izquierda, ya que según éstos habían dado señas de preparación militar y vocación de resistencia. La Dirección de Inteligencia Nacional (DINA) fue creada como una organización encargada de llevar a cabo tales operativos y su misión consistió en exterminar el marxismo y sus ideologías (Salazar, 2011), interrogando, clasificando y separando a los detenidos en los principales campos de concentración ${ }^{3}$.

La relegación ${ }^{4}$ entendida como la permanencia obligada en una determinada localidad del territorio nacional, fue un mecanismo utilizado por la dictadura cívico-

${ }^{1}$ Algunos autores que se han referido a la relegación son: Amunátegui, M. y Amunátegui, V, 1851; Barros Arana, 1889; Rojas, 1993; Moulian, 1997; Huneeus, 2000; Vega, 1999; Acuña, 2015 y Díaz, 2014. Las películas "La Frontera” de Ricardo Larraín y "Dawson, Isla 10" de Miguel Littín.

2 "Inmediatamente después del 11 de septiembre de 1973, el Buque Escuela "Esmeralda" fue utilizado por la Armada de Chile como centro de detención y tortura en el puerto de Valparaíso, según ha sido fehacientemente demostrado por la Comisión Interamericana de Derechos Humanos de la OEA (Informe 24/OCT/74), Amnistía Internacional (Informe AMR 22/32/80), el Senado Norteamericano (Resolución 361-16/JUN/86) y el Informe de la Comisión Nacional (Chilena) de Verdad y Reconciliación (Tercera Parte, Capítulo I, Sección 2 f.2.). Los testimonios de que la "Esmeralda" fue efectivamente usado como cámara de tortura flotante son múltiples y coincidentes". Cita extraída de www.memoriaviva.com; por otra parte, se establece en el Informe de la Comisión Rettig que, una unidad especializada de la Armada de Chile se instaló en el interior del Buque Escuela "Esmeralda" con el objetivo de interrogar a quienes estaban detenidos en la misma nave y a los que eran traídos desde otros recintos de reclusión. Informe de la Comisión Nacional de Verdad y Reconciliación, p. 293.

3 Para mayor información sobre los distintos centros y campos de detención ver: Bitar, 1990; Ehijo y Seelman, 2003; Witker, 1975; Salazar, 2013; Ibáñez, 2013; Bonnefoy, 2005; Vega, 2017; Teitelboim, 2002; entre otros.

${ }^{4}$ En el código penal chileno del 12 de noviembre de 1874, extraído de la página oficial (www.leychile. cl), la "relegación", en el artículo 35, es definida como la traslación del condenado a un punto habitado del territorio de la República con prohibición de salir de él, pero permaneciendo en libertad. A su vez, el informe de la Comisión Nacional sobre Prisión Política y Tortura, argumenta que el concepto es definido 
militar para poder mantener controladas a las personas, de esta forma, en primera instancia nos preguntamos ¿qué papel jugó la relegación como dispositivo de represión?.

Ahora bien, para un mejor entendimiento, es necesario definir a groso modo los conceptos estipulados en el título de este trabajo. Por consiguiente, el concepto de control social para Paul B. Horton y Chester L. Hunt, hace referencia a los medios por los cuales se concibe que las personas desempeñen sus roles como se espera, empezando con el estudio del orden social ya que es dentro de esta en la cual la gente interactúa (Horton y Hunt, 1988: 164-165). De esta forma entonces, cuando se habla de control social, se hace referencia al grupo de normas y regulaciones de diferente tipo que son establecidas explícita o implícitamente por una sociedad para mantener el orden de los individuos y permitir el desarrollo de un nivel de vida organizado y controlado en el plano económico, político, cultural y social.

Según el sociólogo italiano Darío Melossi, el control social ha llegado a convertirse en sinónimo claro de mecanismos de opresión y dominación por parte del Estado y de las clases dominantes, destacando dos tipos de control social importantes, el reactivo -formal- encargado de inhibir la censura, asociándolo a un control de vigilancia y castigo que está representado en las leyes y en la policía; y el activo, que produce un comportamiento en vez de prohibirlo, asociado al control informal ${ }^{5}$ (Melossi, 1985).

De este modo, entenderemos el control social como la aplicación de normas, reglas o recursos del que dispone una sociedad determinada, es decir, la acción o aplicación de todos los recursos que garanticen el orden social, desde sistemas institucionales hasta códigos de conductas, por consiguiente, son las herramientas o mecanismos que puede utilizar ya sea el Estado o grupos políticos que dominan un periodo histórico con el fin de contener cualquier posibilidad de resistencia y desobediencia social anticipándose a los conflictos a través de la internalización del miedo, generando cuestionamientos en el accionar de quienes se les aplica el control.

Con respecto a lo que se expondrá en las siguientes páginas, se aplica el control formal, entendido como vigilante, sancionador y represivo frente a distintos sujetos estigmatizados como desviados, donde el derecho penal cumple funciones de

como el traslado obligatorio de una persona a un lugar distinto al de su residencia habitual, por un plazo determinado por disposiciones administrativas o judiciales. Esta última definición es la que se utilizará en la presente investigación. De esta manera, la relegación se entiende como la restricción de la capacidad de traslado y movimiento en una forma de privación de la libertad de los individuos, por las limitaciones que ella implica y las graves condiciones a que las personas fueron sometidas durante su relegación, muchas de ellas decretadas para ser cumplidas en lugares inhóspitos, aislados, donde los afectados debían procurarse por sí mismos los medios necesarios para su propia subsistencia mientras permanecían bajo controles periódicos de las fuerzas militares o de orden. Además, la relegación implicaba, asimismo, el quebrantamiento de todos los vínculos familiares, laborales y sociales de los afectados.

5 Para un mayor entendimiento, el control formal, según lo expuesto por Melossi, es aquel que prohíbe comportamientos a través de sistemas normativos, por ejemplo, la religión, el derecho, la ética y lo penal, mediante agentes de control que pueden ser, la policía, los juzgados, médicos, entre otros; por otra parte, el control informal, según el mismo autor, produce comportamientos a través de normas sociales como las costumbres, usos populares, tradición, entre otras, por ende, están dentro de lo que el autor denomina los marcos sociales y culturales (Melossi, 1988). 
González Alarcón. Medidas, estrategias y etapas de la relegación durante la dictadura de Pinochet como mecanismo...

control social "además de otras como la de una cierta orientación social, un tratamiento declarado de conflictos y una no menos importante función de legitimación del poder" (Olmo, 2005: 77). Ya que la relegación en los años estudiados se llevó a cabo mediante decretos leyes implementados en la constitución, pasando a ser un control netamente formal y ejercido por las autoridades pertinentes.

En cuanto al concepto de disciplinamiento, para Max Weber, a través de sus estudios sobre el poder, manifiesta que este puede ser entendido como la obediencia habitual por parte de las masas sin resistencia ni crítica (Weber, 2005: 43). De esta forma, según Mantecón, la noción de disciplinamiento implicaría el desarrollo de todo un conjunto de acciones y sensibilidades por parte de los sujetos para acomodar sus comportamientos en sociedad, exigiendo de cierta manera una cultura de la autocensura, la obediencia y el respeto a la tolerancia (Mantecón, 2010: 263-295).

Por otra parte, el disciplinamiento para Michel Foucault, es una forma de poder que tiene como objetivo los cuerpos en sus detalles, su organización interna, la eficacia de sus movimientos. La disciplina entonces, mantiene con el cuerpo una relación analítica, donde, según el filósofo, nos encontramos con una microfísica del poder, cuya finalidad es producir cuerpos útiles y dóciles (Foucault, 1979). En definitiva, es aumentar la fuerza económica del cuerpo reduciendo su fuerza política y, para poder lograr este objetivo, es necesaria la vigilancia, las sanciones normalizadoras (castigos) y la corrección como forma de modificación y transformación de acuerdo a las normas prefijadas.

Queda claro entonces, que para poder entender la definición del concepto de disciplinamiento en Foucault, es necesario tener presente que este está estrechamente relacionado con el poder y este último no se ejerce sólo por la fuerza, sino que, circula por toda la sociedad mediante diversos procedimientos o técnicas de exclusión, control y normalización que permiten disciplinar a la sociedad. Y como ya se mencionó más arriba, el origen del disciplinamiento, del arte del cuerpo, forma un vínculo que, "en el mismo mecanismo, lo hace tanto más obediente cuanto más útil, y al revés" [...] "La disciplina (sic) fabrica así cuerpos sometidos y ejercitados, cuerpos dóciles" (Foucault, 1976: 141). El disciplinamiento aumenta las fuerzas del cuerpo en términos de utilidad $\mathrm{y}$, a la vez las disminuye en términos políticos de obediencia. En una palabra, disocia el poder del cuerpo, hace de este poder una aptitud, una capacidad que trata de aumentar, cambiando por otra parte la energía, y la convierte en una relación de sujeción estricta. Si la explotación económica separa la fuerza y el producto del trabajo, digamos que la coerción disciplinaria establece en el cuerpo el vínculo de coacción entre una actitud aumentada, una dominación acrecentada (Foucault, 1976: 141-142).

Por último, el académico José Joaquín Brunner, siguiendo lo expuesto anteriormente, plantea que estas relaciones de poder en una sociedad autoritaria se convierten en relaciones desiguales que buscan optimizar la producción de la obediencia a través del disciplinamiento, por consiguiente, el control social es ejercido por quienes tienen el poder, convirtiéndose en un instrumento primordial del poder mismo (Brunner, 1980: 9).

En consecuencia y retomando nuestro objeto de estudio, se entiende que los primeros síntomas de relegación se gestaron el mismo año del golpe, cuando un grupo 
amplio de dirigentes políticos de izquierda fueron enviados a Isla Dawson, pero señalando a su vez, que no fue hasta el año 1980 cuando esta práctica se institucionalizó tras la promulgación de una ley que amparó la relegación, justificándola a partir de enunciados que establecieron -según las autoridades militares- que los sujetos relegados alteraban el orden y por ende la instauración de la democracia. Bajo esta premisa, es necesario identificar y comprender, qué medidas se utilizaron para que esta práctica se cumpliera, cuales sujetos fueron sometidos y hacia qué lugares fueron dirigidos, ya sea hacia el extremo norte o sur del país; llevados a poblados pequeños donde muchas veces eran temidos por los lugareños creyendo que eran terroristas, quienes fueron objeto de estas medidas estaban desamparados, producto de que eran relegados de la noche a la mañana sin previo aviso, teniendo que abandonar por completo sus vidas.

Con respecto a la perspectiva historiográfica, nos hemos centrado principalmente en la Historia Reciente ${ }^{6}$, aquella que estudia el pasado cercano, abierto e inconcluso, cuyos efectos se extienden hacia nosotros -presente-(Franco y Levín, 2007). Por ende, es un pasado actual que se encuentra en permanente proceso de actualización y que interviene en las proyecciones futuras.

Para Florencia Levín la Historia Reciente surgió entre mediados y fines de los años noventa para estudiar la historia Argentina de las últimas décadas. Dejando en claro que en términos conceptuales, es un poco difícil decir que es en si la Historia Reciente, debido a que hasta el momento es un tema de debate académico. Según Levín existen:

"A grandes rasgos, dos maneras distintas de concebir lo reciente. En primer lugar, la Historia Reciente está definida por una temporalidad que se delimita por su relación de cercanía con el presente y su objeto de estudio se encuentra en permanente reconstitución por esa relación de coetaneidad entre el sujeto que estudia, el historiador, y su objeto de conocimiento, el tiempo reciente. Sin embargo, en su mayoría, la historiografía concuerda en que la especificidad de la Historia Reciente deviene de algo excesivo, excepcional y novedoso en la historia Argentina, difícil de conceptualizar pero aludido siempre a partir de algunos términos clave como violencia, represión clandestina, terrorismo de Estado, desaparecidos"7.

Suele asociarse entonces, con la noción de trauma. De este modo se podría decir, que es una perspectiva que posee la particularidad de ser parte del mismo fenómeno que estudia.

Por último, como hipótesis planteamos que la relegación en Chile funcionó entre 1973 y 1986, como mecanismo de control social tanto para quien lo sufrió directamente -el relegado- como para su entorno familiar, laboral o colectivo. En ese sentido, como objetivos se buscó analizar la relegación como mecanismo de control

\footnotetext{
6 Para mayor información ver: Franco y Levín, 2007; López, Figueroa y Rajland, 2010; Bresciano, 2010; Águila, 2012; Flier, 2014; entre otros.

7 Marcela Bello. Entrevista con Florencia Levín. 16 de marzo 2015. Recuperado de http://argentinainvestiga.edu.ar/
} 
González Alarcón. Medidas, estrategias y etapas de la relegación durante la dictadura de Pinochet como mecanismo...

social; en segundo lugar, tratamos de caracterizar el contexto histórico en confinados; y por último, contrastar las distintas formas de aplicar el mecanismo.

\section{Contexto histórico nacional}

El clima de tensión, en los días previos al golpe, se agudizaba cada vez más. El sábado 8 de septiembre se había planificado un golpe que debía llevarse a cabo el lunes 10. Sin embargo, se efectuó la mañana del martes 11 de septiembre de 1973. El último discurso del Presidente Allende estuvo dirigido a los profesionales de la patria, mujeres, a la juventud, al obrero, al campesino, al intelectual y a aquellos que serán perseguidos (Verdugo, 2008).

Al mediodía los Hawker-Hunter de la Fuerza Aérea bombardearon La Moneda. Cerca de las 13:20 se produce un cese al fuego. Comienzan a salir por la puerta de calle Morandé 80 quienes hasta ese entonces habían resistido los ataques hacia el Palacio de Gobierno. No obstante, el Presidente Salvador Allende, según la hipótesis más difundida, se había suicidado ${ }^{8}$. De esta manera, la batalla en La Moneda aquel 11 de septiembre de 1973 había finalizado. Se iniciaba ese día el periodo de lo que sería la dictadura de Pinochet.

La ferocidad del golpe ocasionó un vuelco importante en la Unidad Popular ${ }^{9}$, terminando por completo con el Gobierno de Salvador Allende. Dio paso a los 17 años de terrorismo de Estado y las constantes violaciones a los Derechos Humanos. Las rápidas operaciones efectuadas el día 11 de septiembre de 1973 dan cuenta de la planificación anticipada de la insurgencia. A los pocos días el desabastecimiento económico había terminado, milagrosamente aparecieron productos de primera necesidad en el mercado nacional, los recintos utilizados como centros de detención y tortura daban cuenta de haber sido acondicionados con anterioridad (Cavallo, Salazar y Sepúlveda, 2013).

\footnotetext{
${ }_{8}$ La investigación desarrollada por Francisco Marín y Luis Ravanal busca dilucidar la verosimilitud de la versión oficial construida por la Junta Militar respecto de la muerte del Presidente Allende, aquella que se ha sustentado por medio de tres soportes fundamentales: el relato del doctor Patricio Guijón, quién hasta la fecha se ha arrogado la cualidad de único testigo de la muerte; el informe de la autopsia practicada el mismo día del golpe en el Hospital Militar; y el informe de la Policía Técnica de Investigaciones, denominado "Acta de Análisis". Sin embargo, aún existen debates en torno a lo sucedido aquel 11 de septiembre de 1973, en la cual no puede descartarse ninguna hipótesis respecto de la naturaleza de la muerte, entre ellas que hubiera sido causada por terceros, posiblemente por la acción de integrantes del Ejército que participaron del ataque armado al Palacio de La Moneda. En consecuencia, los autores plantean algunas debilidades que giran en torno a la versión oficial de la muerte de Allende, descartando de cierta manera el suicidio (Marín y Ravanal; 2013).

9 Coalición de centro-izquierda que estuvo conformada en primera instancia por el Partido Comunista (PC), Partido Socialista (PS), Partido Radical (PR), Partido Social Demócrata (PSD), Movimiento de Acción Popular Unitaria (MAPU) y la Acción Popular Independiente (API). Sin embargo, durante el gobierno de Allende esta estructura se fue modificando, y desde el PR surgió en 1971 el Partido de Izquierda Radical (PIR); ese mismo año en el MAPU también aparecieron escisiones como la Izquierda Cristiana (IC), y el MAPU Obrero Campesino (MAPU-OC) en 1973.
} 
La Junta Militar a través del Banco $\mathrm{N}^{\circ} 10^{10}$ iniciaba la persecución de todos aquellos partidarios al gobierno de Allende creando las listas de quienes se debían presentar ante las autoridades. También se persiguió a quienes disentían de los procedimientos de la dictadura. Una mínima sospecha los conducía a los campos de concentración, donde se les flagelaba y torturaba; allanamientos de vivienda, con robo constante de pertenencias; delaciones vecinales; exilios y relegaciones (Soto, 1998: 124). La etapa de terror y censura llevó a la suspensión de los partidos políticos y la clausura de la prensa de izquierda. El Bando $N^{\circ} 29$ cerraba el Congreso Nacional, algunos días más tarde se transformó en Decreto Ley (Garretón, 1998).

En palabras de Robert Barros, en medio de la falta de organización militar y legal, las Fuerzas Armadas "emitieron bandos para dar instrucciones a la población civil. Dichos bandos eran edictos penales y administrativos excepcionales sin fundamento constitucional y, según el Código de Justicia Militar, podían ser utilizados en tiempos de guerra para gobernar a las tropas y a los habitantes de los territorios ocupados" (Barros, 2005: 68)

La Junta Militar decidió crear un organismo encargado de llevar a efecto todos los mecanismos de terror. Nace la Dirección de Inteligencia Nacional (DINA) liderada por Manuel Contreras, quien según Manuel Salazar, desde fines de septiembre se había abocado a revisar todos los informes encontrados en las sedes de los partidos de izquierda con el fin de mantener la mayor información e identificación de cada uno de los partidarios (Salazar, 2011: 91). Este organismo comenzó a asumir en propiedad sus nuevas funciones a mediados de octubre de 1973. Fue el encargado de dictar cursos de lucha anti subversiva a las distintas ramas de la policía y Carabineros. Las operaciones se llevaron a cabo a través de la creación de distintas brigadas, cada una con nombres tomados de la cultura mapuche. Con el fin de proteger sus identidades, el trabajo se efectuaba mediante claves y ocultando sus nombres con la utilización de chapas. Tuvo un rápido crecimiento y sus métodos de operaciones comenzaron a ser conocidos en todo el país y en el exterior, generando de esta manera, el terror en la sociedad.

En consecuencia, se puede establecer que la violencia ${ }^{11}$ es entendida como un mecanismo o dispositivo que buscaba la construcción de un determinado orden social. Para eso era necesario de forma gradual, institucionalizar y legitimar dicha violencia y represión como una práctica netamente política, luchando por lograr el orden mediante la guerra interna del amigo-enemigo, la concepción binaria de la sociedad. Así, el régimen podría lograr el disciplinamiento de los individuos a través de los medios de control social, interviniendo los espacios públicos, suprimiendo al sujeto a una mínima expresión, silenciando las voces, confinándolas al espacio privado y alejándolas de lo público. Pero ¿qué tipo de violencia ejerció la dictadura cívico-militar? En primera instancia, es clara la utilización de violencia física y represiva -lesiva-, aquella que

\footnotetext{
${ }^{10}$ Bando $\mathrm{N}^{\circ} 10$ "Orden a lista de dirigentes políticos a presentarse ante las autoridades militares para ser detenidos" con fecha 11 de septiembre de 1973, indicaba lo siguiente: 1. Las personas más adelante nombradas deberán entregarse voluntariamente hasta las 16.30 horas, de hoy 11 de septiembre de 1973 en el Ministerio de Defensa; 2. La no presentación le significará que se ponen al margen de lo dispuesto por la Junta de Comandantes en Jefe con las consecuencias fáciles de prever.

${ }^{11}$ Sobre Violencia Política en Chile, ver: Salazar, 2006; y Lúnecke, 2000; entre otros.
} 
González Alarcón. Medidas, estrategias y etapas de la relegación durante la dictadura de Pinochet como mecanismo...

pretende castigar, interiorizando el miedo en las personas a través de las torturas llevadas a cabo por organismos especializados y aplicados en los campos de concentración y recintos de detención. No obstante aquello, también es posible evidenciar la utilización de violencia simbólica y cultural -coercitiva-, que intentó persuadir a los individuos, como por ejemplo las falsas afirmaciones en la prensa, el tipo de lenguaje que se utilizó, entre otros, cubriendo todas la áreas de acción, ya sea desde el desarrollo económico, hasta la educación o la religión (Monsálvez, 2012: 35-36). Y en último término, la violencia destructiva, cuyo objetivo fue la exterminación.

En consecuencia, existieron dos objetivos claros que mantuvo el régimen para establecer el supuesto orden a través de la violencia. Por un lado, encontramos la reestructuración de la economía, gestando un ordenamiento en los mercados e instaurando como consecuencia el sistema neoliberal (Moulian, 2009), y por otra parte, la reestructuración de la sociedad mediante la fabricación exhaustiva de normas que debía seguir la ciudadanía. Por consiguiente, logró establecer y dominar los procesos de legalización y criminalidad al constituirse como el poder único. Bien lo dice el profesor Monsálvez, logró de esta manera, crear leyes como instrumento para transformar las normas que eran ilegales en normas legales (Monsálvez, 2012).

Pero antes de institucionalizarse, la represión pos 11 de septiembre de 1973, operó siendo dirigida a la exterminación de los principales representantes de la izquierda nacional, es decir, a los líderes de los partidos políticos, los más altos funcionarios del gobierno de Allende, y los miembros del aparato de seguridad personal, conocidos como el Grupo de Amigos Personales (GAP). Sin embargo, la extensión de la represión también abarcó desde autoridades regionales y locales, hasta jefes sindicales, trabajadores, obreros, y estudiantes. En definitiva, todo aquel que se opusiera a los dictámenes del régimen o fuera sindicado de sospechoso, asegurando el control y el dominio de la población (Monsálvez, 2012: 42).

La violencia entonces, penetró en múltiples ámbitos de la vida cotidiana. Tanto física y simbólica tuvieron como objetivo, el disciplinamiento, sosteniendo el orden a través del terror establecido en la ciudadanía. Por tal motivo, la violencia física, se constituye como la represión misma, mientras que la simbólica ${ }^{12}$, se dedicó a controlar

\footnotetext{
${ }^{12}$ Concepto acuñado por el sociólogo francés Pierre Bourdieu en la década de 1970, utilizada para describir una relación social donde el "dominador" ejerce un modo de violencia de forma indirecta y no físicamente directa en contra de los "dominados", quienes no logran evidenciarla o son inconscientes de dicha práctica en su contra (Bourdieu, 1999: 224-225). Es decir, es una violencia que está interiorizada y naturalizada/normalizada hasta tal punto que creemos que las cosas "siempre fueron de esa manera". Por consiguiente, para el autor, la violencia simbólica se realiza por un acto que es de conocimiento -del sentido común-, de re-conocimiento -porque dota de sentido subjetivo ese sentido común-, y de des-conocimiento "al hecho de reconocer una violencia que se ejerce precisamente en la medida en que se le desconozca como violencia [...] aceptar este conjunto de premisas fundamentales, prerreflexivas, que los agentes sociales confirman al considerar al mundo como autoevidente, es decir, tal como es, y encontrarlo natural, porque le aplican estructuras cognoscitivas surgidas de las estructuras mismas de dicho mundo" (Bourdieu y Wacquant, 1995: 120). De esta manera, a modo de ejemplo, en los medios de comunicación es posible identificar la violencia simbólica en todo lo que refuerza los estereotipos siendo responsables de un pensamiento segregacionista, donde todos los segregados son vistos como menos
} 
el funcionamiento del sistema político creando normas, códigos, pautas y conductas. No obstante, es necesario aclarar que la legislación quedaba en manos de las Fuerzas Armadas y no de un poder estatal.

Ahora bien, el miedo ${ }^{13}$ se convirtió en el arma principal de esta relación, instrumentalizada por las elites, medios de comunicación, instituciones, entre otros, controlando y a la vez difundiendo un determinado modelo de sociedad, demarcando lo prohibido de lo permitido (Monsálvez, 2011: 122). Así la dictadura fabricó e instituyó una realidad propia, con normas, conductas y códigos establecidos, con el fin de fabricar individuos normalizados. Pero, ¿Quién es el enemigo en esta guerra (binaria) interna? ${ }^{14}$, para el régimen, fue todo lo que amenazaba a la seguridad propia y al orden social, o sea, lo diferente, lo anormal en palabras de Foucault (Foucault, 2000). Lo anormal en visión de la dictadura, ya que es evidente que lo "normal" no es para todos lo mismo, fue el régimen quien construyó su propia visión de lo que debía ser normal, violentando a quien no lo fuera. Por eso, la pregunta correcta sería, ¿lo diferente para quién?, y la respuesta claramente es para quienes ostentaban el poder.

\section{La relegación durante la dictadura cívico-militar}

Partimos precisando que la relegación no fue un mecanismo utilizado solamente en la dictadura de Pinochet. Los exilios, así como las detenciones con resultados de desaparición, han sido recurrentes a lo largo de la historia nacional (Loveman y Lira, 2000; Portales, 2011). Estas han sido utilizadas como mecanismos de control social, formando parte importante de las prácticas punitivas, aplicadas a las personas que eran

personas por el inconsciente. Así, cuanta menos persona se es, menos derechos y más susceptibles se vuelven a los abusos en todo ambito. Tal es el caso de la violencia simbólica patriarcal (Bourdieu, 1998)

${ }^{13}$ Con respecto al miedo: Para el historiador chileno, Freddy Timmermann, es un elemento esencial en el quehacer humano, es decir, es algo innato que está dentro de nosotros del cual no nos podemos desligar (Timmermann, 2015). En este mismo lineamiento, Norbert Elías manifiesta que es la respuesta psíquica a las coacciones que los hombres ejercen sobre los demás (Béjar, 1991). Por su parte, el profesor Monsálvez llevando el concepto a la práctica en un contexto determinado, nos indica, que el vaciamiento de la sociedad (despolitización) conlleva a que el miedo o los miedos sean instrumentalizados por las elites o grupos de poder, controlando y a la vez difundiendo un determinado modelo de sociedad. En consecuencia, el miedo puede ser entendido entonces como un elemento funcional al dispositivo de poder, debido a que la interiorización de este último y el control transforman a la sociedad en una especie, como lo ha denominado Monsálvez, de "servidumbre voluntaria", normalizada que acata leyes y dictámenes sin cuestionar nada (Monsálvez, 2011). Por consiguiente, la dictadura generó una "cultura del miedo" por tres motivos específicos: la lucha (por el orden); el disciplinamiento de la sociedad: fabricando realidades a través de sus normas, códigos, pautas y conductas; y a través del orden del mercado, es decir de la instauración del sistema neoliberal.

14 “¿Quién es enemigo? Todo lo que amenaza la seguridad propia: lo diferente. Lo diferente demostraría la presencia del caos. Por consiguiente: defender el orden es eliminar lo diferente (...) esto es, se sigue definiendo las relaciones sociales en forma dicotómica: orden versus caos, amigo versus enemigo. Visualizando al caos como un peligro real e inmediato, la defensa del orden exige una 'sociedad cerrada'. En nombre de la unidad se excluye lo diferente. El otro (el enemigo) es expulsado del orden. No tiene 'derecho al Derecho'. Sin ley ni rey, es expropiado de su Derecho Humano fundamental -su pertenencia a una comunidad política por medio de la cual el hombre privado accede a aparecer en público: ser sujeto" (Lechner, 2006: 276). 
González Alarcón. Medidas, estrategias y etapas de la relegación durante la dictadura de Pinochet como mecanismo...

consideradas - por las respectivas autoridades de la época-como peligrosas o enemigos internos de la sociedad.

Para el presente análisis, la relegación es entendida como aquella restricción de la capacidad de traslado y movimiento que tiene una persona o bien una forma de privacidad de libertad que tienen determinados individuos.

Intentaremos esclarecer o estipular que la relegación que impuso la dictadura de Pinochet fue una medida de represión que vulneró los derechos humanos con el objetivo de controlarlos y disciplinarlos. Por consiguiente, es una urgencia poner sobre la palestra e incentivar a nuevos investigadores a trabajar el tema ya que hasta la fecha ha sido poco indagado ${ }^{15}$ debido a que la Comisión Nacional de Verdad y Reconciliación no la consideró como un mecanismo de represión en sí, producto de que dicha Comisión tuvo como labor fundamental establecer un cuadro lo más detallado posible sobre violaciones de los DDHH con resultados de muertes y desapariciones, y frente a esto la relegación se situó como una forma menos grave. Por tal motivo, para nosotros es fundamental que a través de lo que se expondrá a continuación podamos ampliar el conocimiento de los dispositivos de control y represión utilizados en el periodo estudiado.

\section{Dos etapas de la relegación durante el régimen militar}

La relegación estudiada la hemos dividido en dos grandes momentos los cuales es necesario destacar y a su vez explicar de forma detallada, identificando las distinciones entre cada una de ellas. El primer momento va desde 1973 a 1979 y un segundo momento entre 1980 y 1989. De esta manera, entendemos que durante la dictadura cívico-militar, la relegación tuvo dos variantes, una judicial - primer momento- y otra administrativa -segundo momento-. La relegación judicial consistía en "el traslado obligatorio de una persona a un lugar distinto al de su residencia habitual, por un plazo definido, en virtud de una sentencia judicial", es decir, el detenido debía ser sometido a un Consejo de Guerra que lo condenara a dicho castigo, mientras que la relegación administrativa se realiza "sin que haya intervención de un tribunal independiente e imparcial, ni existan cargos en contra de esa persona", invocando como causal: el ser sorprendidos en intentos de alteración del orden público (Acuña, 2015: 15).

Entre 1973 y 1976 periodo de mayor represión del régimen de Pinochet, las relegaciones estuvieron enfocadas en intentar desarticular la cúpula principal de la Unidad Popular, utilizando en primera instancia como lugares para recibir detenidos, la Isla Dawson, Isla Quiriquina, Chacabuco y Pisagua. Con respecto a Dawson, es menester dejar en claro que es una isla pequeña e inhóspita ubicada en el extremo sur del país, requisito primordial para el funcionamiento de la relegación. Cinco días después del golpe, la Armada instaló en este lugar los campamentos de concentración de Rio Chico y Compingin. En este lugar, además de los presos políticos locales, se encontraban algunos ex dirigentes de la Unidad Popular, por ejemplo el ex canciller

\footnotetext{
${ }^{15}$ Para mayor información sobre la relegación en dictadura ver: Aylwin, 1990; Díaz, 2014; Acuña, 2015 y
} González, 2018. 
Clodomiro Almeyda; quien fuera ministro de defensa de la UP, Orlando Letelier; el máximo dirigente del Partido Comunista, Luis Corvalán, y el ex Rector de la Universidad de Concepción Edgardo Enríquez entre otros. Allí no existía prácticamente ningún tipo de acondicionamiento, por lo tanto, se tuvo que construir aquello a través de trabajos obligatorios por parte de los propios prisioneros que ahí se encontraban. Estos trabajos consistían en instalar postes, construir canales, extender alambradas, etc., "un trabajo pesado al que ninguno estaba acostumbrado, como el hecho de cortar árboles con un viento que va más de 100 Kilómetros por hora [...]. La gente estaba en una tensión nerviosa constante, el trabajo era pesado, tenían que cargar piedras y crear murallones [...]"16. De esta forma, el régimen buscaba la rehabilitación de las personas y la reincorporación de estos a las tareas de la patria, quedando manifestado en Revista Ercilla del 23 de octubre de 1973, proclive a la intervención militar (Bitar, 1990).

Después de realizada una visita al campamento ubicado en Isla Dawson, Revista Ercilla manifestó que los prisioneros estaban recuperando su salud, recalcando que los ejercicios obligatorios que estos debían efectuar diariamente, les permitían superar su pasado de sedentarismo, alcohol y cigarrillos. Enfatizando que estos estaban siendo reeducados ${ }^{17}$.

Corresponde señalar que para los primeros años de dictadura cívico-militar, sólo estaba permitido que circulara prensa a favor del régimen, por ende, se entiende lo que intentaba exponer la citada revista.

Por otra parte, entre 1976 y 1979 las relegaciones fueron más focalizadas. En esta etapa de la dictadura aún primaban los exilios y las detenciones con resultados de muerte, este último alcanzó a más de 500 personas $^{18}$, muchas de ellas desaparecidas desde 1973 y encontradas casi a finales de la misma década. No obstante aquello, las relegaciones se mantuvieron enfocadas aún, en personalidades importantes de la política nacional, más bien acotada a determinados casos.

Ahora bien el Decreto Ley número 12 de 1973 hablaba de pena de "presidio, relegación o extrañamiento mayores en cualquiera de sus grados" 19 para personas que no cumplieran o acataran una determinada norma, pero no será hasta febrero de 1980 cuando aparezca específicamente la relegación administrativa por medio del Decreto Ley número 3.168, en el cual se estipuló que el Ministerio del Interior podía disponer del traslado y permanencia de una persona "sin necesidad de sostener un trámite judicial en una localidad alejada y de poca población, generando desconexión del círculo social y teniendo que aprender a vivir a veces en malas condiciones económicas y de salud" (Díaz, 2014: 3). De esta forma:

"El seis de febrero entró en vigencia el Decreto Ley número 3.168, del Ministerio del Interior. El mencionado decreto ley faculta al gobierno para disponer la permanencia obligada en una determinada localidad

\footnotetext{
${ }^{16}$ José Tohá, víctima inocente de la violencia. Revista Chile-América, diciembre de 1974, en suplemento $\mathrm{N}^{\circ} 1$, año 1, pp. 5-14.

${ }^{17}$ Los de Dawson y los otros. Revista Ercilla, 23 de octubre de 1973, pp. 15-18.

${ }^{18}$ Ver Revista Solidaridad, ${ }^{\circ} 17,21$ y 27.

${ }^{19}$ Decreto Ley $N^{\circ} 12$, "Cancelación personalidad jurídica de la CUT"
} 
González Alarcón. Medidas, estrategias y etapas de la relegación durante la dictadura de Pinochet como mecanismo...

del territorio nacional de las personas que alteren o pretendan alterar el orden público, por un plazo no superior a tres meses. Esta medida -agrega el Decreto- sólo podrá adoptarse mediante decreto supremo firmado por el Ministro del Interior, bajo la fórmula por orden del Presidente de la República"20.

La relegación administrativa a diferencia de la judicial tenía un plazo no superior a tres meses. María Graciela Acuña, argumenta que estuvo enfocada a "estudiantes universitarios, secundarios, obreros, pobladores y, minoritariamente profesionales. En su mayoría eran del sexo masculino, nivel técnico, obrero, de escasos recursos económicos" (Acuña, 2015: 24). Teniendo la intención de alejar a dirigentes sindicales y desarticular rápidamente a los movimientos de oposición al régimen.

Es a través de este decreto ya aludido que la dictadura buscaba revestir sus medidas represivas con un manto de legalidad. Era claro el interés que suscitaba para los militares cubrir sus acciones bajo alguna forma legal. Y en un país como Chile de una larga trayectoria legalista hasta las mayores ilegalidades buscaban justificarse.

\section{Procedimientos de detención y relegación}

A partir del mismo 11 de septiembre de 1973 se desplegó una clara estructura represiva, que recurrió a todo método y forma posible de desarticular, neutralizar y eliminar al supuesto enemigo interno (Cavallo, 2013).

Las detenciones a cargo de la DINA en primera instancia y de la CNI en la década de los ochenta se realizaron a través de allanamientos, detenciones -masivas y selectivas- en la vía pública o en sectores privados y presentaciones voluntarias anunciadas por bandos militares (Salazar, 2012). José Caucamán fue detenido el día 19 de septiembre de 1973 al interior de un supermercado y dejado sin comunicación a partir de ese momento. Estuvo tres meses en la prisión de Chin Chin, donde fue torturado e interrogado reiteradamente para luego ser relegado a la localidad de Tal Tal. Por su parte Eugenio Gutiérrez, estudiante de ingeniería comercial de la Universidad de Santiago de Chile, fue relegado a Salamanca en 1984 tras un allanamiento masivo donde tomaron detenidos alrededor de unos quinientos estudiantes por efectivos de la Central Nacional de Informaciones $(\mathrm{CNI})^{21}$.

Las detenciones por su parte se intensificaron en fechas de mayor efervescencia política. De esta manera, a tan solo un par de días de la aparición en la opinión pública de las nuevas facultades adoptadas por el régimen con respecto a la ley 3.168, se había dispuesto la relegación de 12 de las 136 personas que fueron detenidas durante las manifestaciones en conmemoración del Día Internacional de la Mujer. Así la dictadura manifestaba que "cuando la gente no entiende con buenas palabras, entiende con hechos" ${ }^{\prime 2}$. Y a repercusión de lo señalado, la pregunta que comenzó a surgir en varios

\footnotetext{
${ }^{20}$ ¿Estado de sitio? Reestreno de la relegación. Revista Solidaridad, segunda quincena febrero, 1980, p. 4.

${ }^{21}$ ¿Estado de sitio? Reestreno de la relegación. Revista Solidaridad, segunda quincena febrero, 1980, pp. 33-36.

${ }^{22}$ Relegaciones. Revista Solidaridad, primera quincena de marzo de 1980, p. 2.
} 
sectores en marzo de aquel año, fue ¿Cuál es el delito de las personas que se reunieron el sábado 8 de marzo para conmemorar el Día Internacional de la Mujer? Por su parte, la comisión de Derechos Humanos señalaba que el régimen se había sobrepasado en el rigor de las sanciones ${ }^{23}$.

Sin embargo, las relegaciones comenzaban a aumentar y lo relatado en el párrafo anterior se repetía en distintas fechas, como por ejemplo el $1^{\circ}$ de mayo y el 11 de septiembre de cada año - cuando el régimen conmemoraba el golpe de Estado-. Por consiguiente, la historiadora María Graciela Acuña plantea que, en el primer año de relegación administrativa hay registros dentro de los archivos de la Fundación de Ayuda Social de las Iglesias Cristianas (FASIC) de 91 relegados a nivel nacional, mientras que Eduardo Díaz en su revisión de archivos manifiesta que podrían haber excedido los 100 relegados.

Posterior a las detenciones se procedía al traslado de los sujetos a los respectivos centros de reclusión acondicionados para los interrogatorios a través de mecanismos vejatorios y torturas. En los primeros años de dictadura, estas detenciones duraban meses o años antes de que se decidiera relegarlos por sentencia "judicial" a 541 días. Manuel Rodríguez por ejemplo, fue enviado a la localidad de Bulnes en la provincia de Chillán región del Biobío 18 meses después de su detención, lo cual significa que debió haber estado recluido en algún campo de concentración en la zona norte del país. Por su parte, la fórmula administrativa de 1980 poseía como regla de detención en algún recinto de reclusión, no más de 5 a 20 días. Posterior a esto debían ser trasladados por Policía de Investigaciones (PDI) a algún punto del país, para luego ser entregados a Carabineros quienes ejercían como autoridad en los lugares de relegación.

Félix Avilés da cuenta de su detención en 1984, una detención masiva pero selectiva en la Universidad Católica de Santiago por efectivos de la CNI. Argumenta que:

"[...] ahí comienza mi periplo por las comisarias e Investigaciones y terminó un día a las 4:00 de la mañana más o menos y nos sacan de Gendarmería, bah, de Investigaciones en un bus y sin saber pa'donde" 24.

En los diez días que pasó entre comisarías y cuarteles de Investigaciones le aplicaron torturas, vejámenes y humillaciones.

"Es jodido eso, entonces yo tuve esa experiencia súper fuerte, antes de irme relegado, en que algún momento yo pensé que me mataban y me entregue" 25 .

El traslado de los pocos detenidos en la década de los setenta se realizó a través del aire. Los detenidos al llegar al aeropuerto de "Los Cerrillos" en Santiago, utilizado sólo para vuelos nacionales, tenían la certeza de que estaban siendo relegados, aunque

\footnotetext{
${ }^{23}$ Gobierno, tiempo de dureza. Revista Hoy, N 139 del 19 al 25 de Marzo de 1980, p. 7.

${ }^{24}$ Entrevista a Félix Avilés en (Acuña, 2015, 45).

${ }^{25}$ Entrevista a Félix Avilés en (Acuña, 2015, 45).
} 
siempre con el miedo latente de que pudiesen ser arrojados al mar. Por su parte, aplicada la relegación administrativa a comienzos de 1980 esta aumenta significativamente, por lo que era muy costoso seguir con el traslado vía aérea, se opta entonces por el traslado masivo ya sea en tren o bus costeado por los mismos sentenciados.

Juan Polizzi detenido en Concepción manifiesta que:

"El tema de la relegación es que después nos llevaron a Santiago, a cómo es que se llama, a investigaciones y..., investigaciones en Santiago en ese tiempo, no se ahora, pero andaban con boinas negras, armados que se yo, y era escalofriante entrar a los cuarteles, y ahí te hacen tocar el piano (las huellas), fichaje de nuevo. Pero toda esta cosa de los fichajes era más para amedrentar que, más que nada. Y nos cargan al bus nuevamente y partimos hacia el norte"26.

Policía de Investigaciones custodiaba a los relegados y los iban dejando en sus respectivas localidades de castigo.

"Bueno ahí se distribuyó, porque ahí llegaron de todo el país, estaba lleno, porque llegó gente de todo el país. Ya estos dos pa acá, estos pa allá, al bus de acá. A los que van pal norte, los del sur iban pal norte y los del norte iban pal sur. Y claro llegamos, nosotros llegamos a Ovalle, de Ovalle nos mandaron, nos fueron a dejar en vehículo los detectives. También nos ficharon ahí en Ovalle, y nos llevaron a Punitaqui”27.

Llegados a su lugar de relegación la responsabilidad de estos recaía en Carabineros de la localidad, estos ejercían la autoridad, el control y la vigilancia. Se les anunciaba las restricciones a las que debían ser sometidos.

"Nos dejan en la comisaria, en la tenencia y el teniente, no, el carabinero a cargo dice, ya ustedes mañana en la mañana tienen que conversar con mi teniente, el anda en Ovalle pero vuelve mañana y hoy día tienen que buscar donde alojarse y aquí no pueden hacer nada, no pueden hablar con la gente, no pueden trabajar, no pueden hacer ninguna cosa" 28 .

De esta forma, debían someterse a vigilancia y control policial constante, permaneciendo de manera obligatoria dentro del pueblo con prohibición de salir de él, pudiendo trabajar en algunos casos puntuales, en cualquier actividad remunerada, que no sea fiscal, semi fiscal o municipal, ya que los relegados no poseían fuentes de ingreso, eran detenidos y relegados con lo puesto.

\footnotetext{
${ }^{26}$ Entrevista a Juan Polizzi, 16 de junio de 2017.

${ }^{27}$ Entrevista a Juan Polizzi, 16 de junio de 2017.

${ }^{28}$ Entrevista a Juan Polizzi, 16 de junio de 2017.
} 


\section{Sujetos y lugares de relegación}

Con el objetivo de desarticular y eliminar todo rastro de oposición o resistencia en contra del régimen, los militares persiguieron, detuvieron y reprimieron a los altos cargos de la Unidad Popular.

A isla Dawson fueron enviados personalidades importantes de la cúpula principal de la UP quienes como ya se mencionó, fueron los encargados de acondicionarla como campo de concentración. En Quiriquina también acondicionada por los propios detenidos, llegaron políticos, militantes y simpatizantes del gobierno derrocado, todos ellos provenientes de la misma región del Biobío. Por su parte, en Pisagua se repetía lo ocurrido a mediados del siglo XX, ya que volvió a recibir a muchos militantes comunistas.

No obstante aquello, controlados y desarticulados los partidos principales de oposición al régimen, se comienza a reprimir a dirigentes democratacristianos que según la dictadura de Pinochet, estaban prestando ayuda a extremistas y revolucionarios, y que eran más proclive a las ideas izquierdistas. Guillermo Yungue (DC) ex presidente de la Federación de Estudiantes Secundarios de Santiago (FESES) durante el gobierno de Allende, después del golpe vincula sus actividades políticas a los movimientos de defensa de los derechos humanos. Ya en 1977 encabezaba las primeras manifestaciones en contra del régimen militar. En 1978 fue relegado junto a 12 dirigentes del PDC a localidades del altiplano chileno cercano a la frontera con Bolivia (Aylwin, 1990). De esta forma, se relegaba para fines de la década de 1970 a ex parlamentarios, dirigentes sindicales y juveniles ${ }^{29}$.

Las localidades más recurrentes fueron Codpa, Chapiquiña, Chucuyo, Parinacota y Guallatire. Aquellas estaban a más de 4 mil metros sobre el nivel del mar. El invierno Altiplánico era crudo. La altura provocaba malestar en los detenidos, asfixias y falta de aire. La vida en ciudad los había acostumbrado a una determinada alimentación, por lo que les fue complejo adaptarse.

En resumen, las relegaciones se efectuaron en lugares aislados, inhóspitos y alejados de la conurbación central del país. Post golpe se centró en sujetos políticos importantes de la izquierda o de oposición al régimen, quienes fueron enviados al extremo sur, y principalmente al norte en la frontera con Bolivia. También es posible encontrar obreros, mineros, estudiantes universitarios, vendedores y comerciantes. En esta época como ya nos referimos, fue bastante focalizada, existiendo una cantidad menor de relegados a diferencia de lo ocurrido en 1980.

En la primera etapa de dictadura primaron los exilios (Del Pozo, 2006 y Rebolledo, 2006). Se estipula que salieron para esas fechas más de 200 mil chilenos, en su mayoría: políticos importantes, dirigentes sindicales y simpatizantes de izquierda. De esta manera, a comienzos de 1980 cuando el régimen en su intento por legalizar los mecanismos represivos dictando la ley sobre relegación administrativa, la cúpula principal de la UP ya estaba desarticulada. Por ende, el objetivo de esta fue frenar el

\footnotetext{
${ }^{29}$ Finalizaron relegaciones, volvemos fortalecidos. Revista Solidaridad, primera quincena de marzo, 1978, 14.
} 
González Alarcón. Medidas, estrategias y etapas de la relegación durante la dictadura de Pinochet como mecanismo...

naciente movimiento social que se estaba gestando. Se relegó entonces a: profesores (as), abogados (as), empleados (as), dirigentes sindicales, estudiantes, pobladores, entre otros, a todo aquel que intentase por cualquier medio alterar el orden establecido sin distinción alguna ${ }^{30}$.

Los relegados provenían de ciudades importantes del país, como por ejemplo: Arica, Antofagasta, Valparaíso, Santiago, Concepción y Temuco. Enviados en el sur a: Freirina, Corral, Maullín, Purén, Los Sauces, Fresia, Curacautín, Panguipulli, Futrono, Chonchi, entre otras. Y en el norte: Mamiña, Sierra Gorda, Chapiquiña, Huara, Punitaqui, Pisagua, y otras. Todas ellas eran localidades alejadas de los principales centros urbanos, inhóspitas y de poca población, lo que hacía más fácil el control y vigilancia de los detenidos.

La relegación estaba enfocada -señaló el periodista Ignacio González- tanto a nacionales como también a extranjeros, en otras palabras a todos aquellos "que en alguna medida vulneren o amenacen la paz social imperante en el país"31. Agregando, que el Ministro del Interior Sergio Fernández no descartaba totalmente el exilio, sino que se pretendía dar preferencia al traslado de una persona dentro del mismo país y con un plazo máximo de tres meses. De esta forma, la dictadura pinochetista a comienzos de los años ochenta optó, por sobre la expulsión del país, por el traslado de las personas de un lugar a otro dentro del territorio nacional; además, el régimen manifestó tener la convicción de cumplir uno de sus más elementales deberes: prevenir todo riesgo en el camino hacia una nueva democracia que pretendía construir, por ende, asegurar la paz y la tranquilidad de los chilenos durante la actual administración ${ }^{32}$.

\section{Trato de los detenidos: Desde su detención hasta su lugar de relegación}

Una de las principales características del régimen, es la violencia con la cual se intentó controlar y disciplinar a la población. La tortura buscaba interiorizar el miedo en las personas para que estas actuaran acorde a lo establecido por la Junta Militar. Los lugares que se acondicionaron para detener y castigar; las organizaciones creadas como la DINA y posteriormente la CNI; y los mecanismos utilizados, dan cuenta, que desde el mismo día del golpe las violaciones físicas a los derechos humanos se hicieron presentes (Huneeus, 2000). Por su parte, las autoridades de la época y los civiles proclives a la dictadura siempre lo negaron. En consecuencia, en 1983 el para ese entonces ex General Gustavo Leigh manifestaba que en Chile estaba prohibida la tortura $^{33}$. No obstante aquello, las numerosas denuncias efectuadas por el Comité Pro Paz indicaban lo contrario, algo que no se podía negar, ni menos ocultar. Para 1974 existían 154 denuncias de malos tratos, y torturas en los lugares de detención.

\footnotetext{
${ }^{30}$ Las características de los sujetos relegados para dicho periodo se extrajeron de la revisión de los Archivos de la Fundación de Ayuda Social de las Iglesias Cristianas (FASIC).

${ }^{31}$ Gobierno, ¿Vuelta al estado de sitio?, Revista Hoy, 13 de febrero de 1980, 7.

32 ¿Estado de Sitio? Reestreno de la relegación. Revista Solidaridad, segunda quincena de febrero de 1980, p. 4.

33 Tortura, todos somos culpables. Revista Cause, 6 de diciembre de 1983, pp. 27-29.
} 
En 1983 de los 11 torturados en el mes de julio, la mayor parte correspondía a un grupo de dirigentes sindicales relegados al sur ${ }^{34}$. Esto quiere decir, que sumado al desarraigo de su entorno social y familiar, el relegado tuvo que pasar en la mayor parte de los casos, por bastantes apremios físicos, tratos crueles y degradantes que los llevaron a tener una mala estadía en sus lugares de castigo (Rebolledo, 2012). Los interrogatorios/ torturas en los cuarteles de la CNI consistían en saber de sus vidas privadas, laborales, sindicales y sus vinculaciones partidistas. Testimonios dan cuenta de los infiernos que vivieron en aquellos días. El 19 de mayo de 1980, Humberto Espinoza Aravena fue detenido en Valparaíso por tres sujetos, siendo uno de ellos miembro de la Armada. Luego de ser golpeado en la vía pública alrededor de las 23 horas fue trasladado a la asistencia estatal y posteriormente entregado a Carabineros. Tras casi 5 días detenido se le aplicó la medida de relegación ${ }^{35}$. Así también constatamos que los apremios físicos iniciaban desde el mismo momento de las detenciones.

En la década de los 80 los arrestos aumentaban en los actos masivos. La represión era grave y delicada. Y si bien, el exilio había disminuido gradualmente mediante la política del retorno, la relegación se había constituido como el mecanismo primordial de control social. (Ver cuadro 1)

Cuadro 1. Balance de la represión en 1982

\begin{tabular}{ll}
\hline Arrestos individuales & $\mathbf{3 1 2}$ \\
\hline Arrestos en manifestaciones colectivas & 901 \\
\hline TOTAL ARRESTOS & 1.213 \\
\hline Amedrentamientos & 125 \\
\hline Apremios ilegítimos (sólo los denunciados a los Tribunales) & 57 \\
\hline Relegaciones administrativas (sin intervención de Tribunales) & 66 \\
\hline Expulsiones & 4 \\
\hline
\end{tabular}

Fuente: Revista Solidaridad, primera quincena de enero de 1983.

El cuadro que indica el balance de la represión para fines de 1982 deja entrever la asonada callejera que se estaba comenzando a gestar para el periodo, producto del malestar social de la crisis económica y de las respuestas negativas sobre los detenidos desaparecidos. Los arrestos colectivos superaban con creces a los individuales. No obstante, las estadísticas de estos arrestos sólo registran los casos atendido por el Departamento Jurídico de la Vicaría de la Solidaridad. Por lo tanto, quizás los números pueden variar un poco en la realidad nacional. Sin embargo, cumplen la función de esclarecer el aumento significativo de las medidas represivas.

\footnotetext{
34 1973-1983 Bitácora de la tortura. Revista Cause, 6 de diciembre de 1983, pp. 30-31.

35 ¡Ultima hora! Nuevos relegados. Revista Solidaridad, segunda quincena de mayo de 1980, p. 2.
} 
González Alarcón. Medidas, estrategias y etapas de la relegación durante la dictadura de Pinochet como mecanismo...

En los años venideros esto se acrecienta. En 1983 Sergio Onofre Jarpa, quien había asumido el mando del Ministerio del Interior, intensificó las medidas represivas en las jornadas de protestas nacionales, con el objetivo de frenar y reprimir el naciente movimiento social que se estaba gestando, instalando el estado de sitio, aumentando los allanamientos, los falsos enfrentamientos, las detenciones e intensificando las relegaciones (Iglesias, 2011), y sólo entre octubre y noviembre de 1984, más de 560 personas habían sido relegadas a distintos puntos del país. La población había comenzado a perder el miedo y por ende, se alzaba en contra del régimen de una forma mucho más concreta de cómo se había estado desarrollando en años anteriores ${ }^{36}$.

Por otra parte, los malos tratos continuaban muchas veces en sus lugares de relegación. Las violaciones a los derechos humanos no sólo se efectuaban de forma física, sino también sicológicas: como por ejemplo, las restricciones de movimientos, vigilancia, control permanente, y otros. Cabe mencionar entonces, que los relegados tenían que presentarse a firmar en sus respectivos retenes, dos o tres veces por día con el fin de poder mantenerlos controlados y que estos no pudiesen salir del pueblo. Por consiguiente, Acuña plantea que "son restricciones que fueron impuestas en las distintas localidades, que aseguraban que el relegado permaneciera ajeno a la sociabilidad local" (Acuña, 2015: 21). En otras palabras, se esperaba que estos no politizaran a los lugareños.

En consecuencia, para poder permitirnos una comprensión mayor del impacto y de las implicancias que la relegación tuvo para quienes fueron afectados por ella. Es necesario descubrir la polisemia de la experiencia. "En tanto para unos, fue -como es predecible pensar- una vivencia dolorosa, signada por la arbitrariedad, la violencia y la segregación, para otros fue una oportunidad de compartir con las comunidades locales de apartados y pequeños poblados del país, en espacios y tiempos comunitarios y solidarios" (Acuña, 2015: 10). Contrastes que pueden ser explicados por diversos factores, como aquellos factores externos que terminaron por ser decisivos en la experiencia de los relegados. Un ejemplo fueron los poblados que estaban gobernados por autoridades, ya sea civiles, policiales o eclesiásticos proclives a la dictadura. Estos por lo general creaban condiciones desfavorables para los relegados. De este modo, vivían la experiencia con limitados vínculos con la comunidad, restringidos en el espacio que podían transitar y habitar. En estos casos las emociones más recurrentes fueron de soledad y angustia.

Algunos relatos obtenidos dan cuenta de recurrentes encierros por parte del personal policial en las piezas de las pensiones en las que se alojaban; impedimentos en conversaciones con personas del lugar; restricciones en el espacio que podían circular y muchas veces siendo seguidos por Carabineros; en algunas localidades las autoridades prohibieron a trabajadores del Programa de Empleo Mínimo (PEM) tener contacto con los relegados; y campañas ejercidas por personal policial para desprestigiar moralmente

\footnotetext{
${ }^{36}$ La pérdida del miedo, y el incremento del malestar social gestaron lo que se conoce como las Jornadas de Protestas Nacionales desarrolladas entre 1983 y 1986, ver: Campero, 1987; Garcés y De la Maza, 1985; Garcés y Leiva, 2005; Guillaudat y Mouterde, 1998; Valdivia, Álvarez y Pinto, 2008; Weinstein, 1989; e Iglesias, 2011.
} 
a estos entre los vecinos, señalando que eran peligrosos. Un testimonio lo describe de la siguiente manera.

"Yo estoy en un pueblo y me puedo mover. Eso podría parecer ante muchos ojos como algo grato. Puedo caminar, convivir con la gente y no salir de este lugar. No puedo salir, esa es la cosa. Dentro yo vivo "libre". Pero esta libertad que permite el sistema es falsa, es un engaño, un engaño que viven muchos chilenos, que pueden moverse, consumir ciertas cosas. No sufren la represión directamente. Pero están engañados, porque si están reprimidos. Todo esto puede parecer libertad, pero no lo es. En definitiva es una cárcel. Una cárcel física y de conciencia. Una cárcel que impide plantearme como ser humano, crear, opinar, expresarme" (Acuña, 2015: 12).

Por otra parte, existen testimonios que manifiestan las buenas acogidas al momento de sus llegadas, ya sea por los habitantes como también por los párrocos de las iglesias; algunos tuvieron la suerte de obtener trabajos en el PEM. Dentro de todo esto, muchos reflexionaban en que aquella situaciones que estaban viviendo lejos de sus familias, les ayudaba a reafirmar sus compromisos de seguir luchando por la justicia y la libertad, dando cuentas que su lucha era justa y que no dejarían de seguir intentando generar un cambio en el país. Por ende, no significaba un apagón para ellos, sino todo lo contrario. Además, no contaban sólo con el apoyo de los lugareños y de sus compañeros relegados, sino también con el apoyo de todo el país que se manifestaba en oposición a lo que estaba ocurriendo. Miles de chilenos les enviaban cartas solidarizando con el compañero relegado ${ }^{37}$.

El objetivo de este mecanismo fue en palabras del régimen, la rehabilitación y recuperación de los sujetos desviados a las tareas de la patria. De esta forma, los lugares alejados jugaron el papel de prisiones con el fin de mantenerlos controlados, y el constante desgaste sicológico que estos debían sufrir tenía que ser suficiente para disciplinarlos.

\section{Algunos casos de relegación durante la dictadura cívico-militar}

La relegación, si bien se constituyó como uno de los principales mecanismos de represión y control social durante la dictadura, y como lo hemos venido anunciando, no fue el más utilizado en la primera etapa del régimen. Ya quedó establecido que los lugares recurrentes a días del golpe fueron Pisagua, isla Dawson, Chacabuco e isla Quiriquina y que hasta allí llegaron políticos, ex políticos y militantes importantes de la Unidad Popular. Primando en esta época, los exilios y desapariciones. Este último, con fecha 20 de agosto de 1976, se da conocimiento a la opinión pública de 383 casos de personas desaparecidas, de las cuales, 337 desaparecieron entre el 11 de septiembre de

\footnotetext{
${ }^{37}$ Relegados el otro exilio. Revista Solidaridad, segunda quincena de mayo de 1980, p. 13.
} 
González Alarcón. Medidas, estrategias y etapas de la relegación durante la dictadura de Pinochet como mecanismo...

1973 y el 31 de diciembre de 1975. Mientras que los 46 restantes ocurrieron entre el $1^{\circ}$ de enero y el 30 de junio de $1976^{38}$.

En diciembre de 1977 siete dirigentes sindicales fueron relegados a diferentes localidades del norte del país ${ }^{39}$. En Chapiquiña, lugar donde llegaron, los habitantes los observaban en un primer momento con desconfianza, creyendo que eran terroristas. Posteriormente se enteraron por radios extranjeras que no eran sujetos peligrosos, sino simples dirigentes sindicales que habían tenido una actitud crítica y de oposición hacía el régimen y por ello fueron sancionados por las autoridades. Fue entonces, cuando los lugareños comenzaron a acercarse a ellos con mayor confianza, incluso gestando algunas relaciones de amistad. No obstante aquello, Manuel Sepúlveda y Héctor Cuevas en conversaciones con Solidaridad, manifestaron lo mal que lo pasaron debido a la gran altura de los pueblos donde habían sido enviados.

Un año más tarde, en enero de 1978 fue detenido Andrés Aylwin junto a 12 miembros de la Democracia Cristiana ${ }^{40} \mathrm{y}$ enviados por disposición del Supremo Gobierno a diversos lugares en el Altiplano en la frontera con Bolivia (Aylwin, 1990: 33).

Tras su detención, los dirigentes desconocían cuál sería su destino, sólo tenían certeza que existían tres opciones: el exilio, por lo tanto la concerniente expulsión del territorio nacional, la relegación a alguna localidad del país o bien la muerte como a la fecha ocurría con un número significativo de personas. En medio de aquella incertidumbre fueron sometidos a interrogatorios y tratados como delincuentes comunes.

Tras su interrogatorio, su destino seguía siendo incierto, hasta que días después, alrededor de las cinco de la madrugada fueron llevados hacia el aeropuerto de "Los Cerrillos", destinado exclusivamente a vuelos nacionales. Allí se les comunicó que por disposición del Supremo Gobierno debían ser relegados a diversos lugares en el norte del país. Localidades como Codpa, Chapiquiña, Chucuyo, Parinacota y Guallatire. Además se les comunicó que habían sido sorprendidos en actuaciones delictuales contra la seguridad del Estado, y que por lo tanto el Supremo Gobierno había acordado su traslado y no encarcelación, como una forma de contribuir a su rehabilitación y posterior reincorporación a las tareas de la Patria.

Sin embargo, la medida de relegación en la década del 70 no sólo afectó a personas importantes del mundo político o a dirigentes sindicales, sino también al ciudadano de a pie: obreros, estudiantes, comerciantes, pobladores, jóvenes, entre otros (Ver cuadro 2). Así a comienzos de 1978 cuatro jóvenes universitarios fueron relegados por repartir panfletos en oposición a la dictadura. Todos ellos fueron detenidos la noche del día 3 de enero y sentenciados por Consejo de Guerra a penas de relegación: Manuel

\footnotetext{
${ }^{38}$ Informe sobre 383 casos de personas desaparecidas. Revista Solidaridad, octubre de 1976, p. 4.

${ }^{39}$ Después de la relegación, la moral aumenta. Revista Solidaridad, primera quincena de enero, 1978, pp. 10-11.

${ }^{40}$ Guillermo Yungue, Tomás Reyes, Andrés Aylwin, Belisario Velasco, Samuel Astorga, Juan Manuel Sepúlveda, Enrique Hernández, Hernán Mery, Ignacio Balbontín; Elías Sánchez, Juan Claudio Reyes y Georgina Aceituno.
} 
Cartes y René Durandeau fueron condenados a 600 y 61 días, mientras que Alejandro Darío Zuleta Marín y Álvaro Fischer a 600 y 541 días respectivamente ${ }^{41}$.

El malestar social a fines de la década de 1970 era latente. La población comenzaba a manifestarse en las calles sabiendo que las consecuencias de esta serían la cruda represión por parte de las autoridades. La cantidad de detenidos aumentaba. Los manifestantes demandaban el restablecimiento de las libertades fundamentales, el término de las medidas de excepción, creación de una Asamblea Constituyentes, entre otras.

Cuadro 2. Tabla de algunos relegados en la década de 1970

\begin{tabular}{|c|c|c|c|c|c|c|c|}
\hline 昜 & 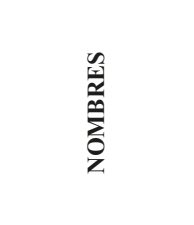 & 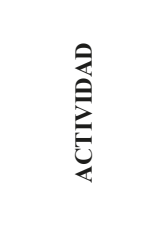 & 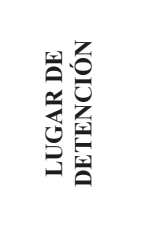 & 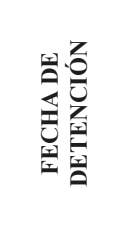 & 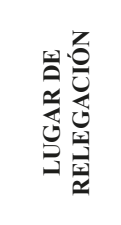 & 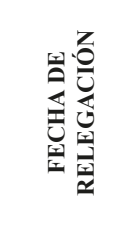 & 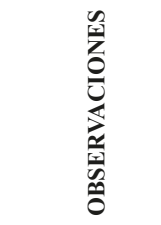 \\
\hline $\begin{array}{l}\text { ÁLVAREZ } \\
\text { QUINTEROS }\end{array}$ & LUIS ENRIQUE & $\begin{array}{l}\text { Estudiante } \\
\text { Universit. }\end{array}$ & Antofagasta & 11.09 .1973 & $\begin{array}{l}\text { Castro } \\
\left(10^{\mathrm{a}} \mathrm{R}\right)\end{array}$ & 00.11 .1973 & $\begin{array}{l}\text { Relegado por } \\
\text { Consejo de } \\
\text { Guerra }\end{array}$ \\
\hline $\begin{array}{l}\text { ARANCIBIA } \\
\text { PACHECO }\end{array}$ & $\begin{array}{l}\text { ÓSCAR } \\
\text { ARNALDO }\end{array}$ & $\begin{array}{l}\text { Chofer } \\
\text { Mecánico }\end{array}$ & Antofagasta & 23.11 .1973 & $\begin{array}{l}\text { Tocopilla } \\
\left(2^{\mathrm{a}} \mathrm{R}\right)\end{array}$ & 05.01 .1974 & $\begin{array}{l}\text { Relegado por } \\
\text { Consejo de } \\
\text { Guerra }\end{array}$ \\
\hline $\begin{array}{l}\text { COVARRUBIAS } \\
\text { CORTÉS }\end{array}$ & RENÉ & Comerciante & Los Ángeles & 24.09 .1973 & $\begin{array}{l}\text { Molina } \\
\left(7^{\mathrm{a}} \mathrm{R}\right)\end{array}$ & 28.07 .1975 & \\
\hline $\begin{array}{l}\text { DEL CANTO } \\
\text { RODRÍGUEZ }\end{array}$ & ANA LUISA & $\begin{array}{l}\text { Técnic } \\
\text { Desarrollo } \\
\text { Rural }\end{array}$ & La Serena & 17.09 .1973 & $\begin{array}{l}\text { La Ligua } \\
\left(5^{\mathrm{a} R}\right)\end{array}$ & 27.12 .1973 & $\begin{array}{l}\text { Relegado por } \\
\text { Condena }\end{array}$ \\
\hline ROJAS CAMPOS & $\begin{array}{l}\text { SOLIER } \\
\text { HUMBERTO }\end{array}$ & Sastre & Salamanca & 17.09 .1973 & $\begin{array}{l}\text { Huasco } \\
\left(3^{\mathrm{a}} \mathrm{R}\right)\end{array}$ & 06.04 .1974 & $\begin{array}{l}\text { Relegado por } \\
\text { Consejo de } \\
\text { Guerra }\end{array}$ \\
\hline $\begin{array}{l}\text { RAMÍREZ } \\
\text { AGUAYO }\end{array}$ & LUIS & $\begin{array}{l}\text { Administrador } \\
\text { de Hotel }\end{array}$ & Antofagasta & 10.07 .1974 & $\begin{array}{l}\text { Lonoche } \\
\left(9^{\mathrm{a}} \mathrm{R}\right)\end{array}$ & 20.03 .1975 & $\begin{array}{l}\text { Relegado por } \\
\text { Condena }\end{array}$ \\
\hline $\begin{array}{l}\text { MENDOZA } \\
\text { MUÑOZ }\end{array}$ & RAÚL & $\begin{array}{l}\text { Deleg. Prov. } \\
\text { Desarrollo } \\
\text { Social } \\
\end{array}$ & Osorno & 29.03 .1977 & $\begin{array}{l}\text { Chanco } \\
\left(7^{\mathrm{a}} \mathrm{R}\right)\end{array}$ & 14.04 .1977 & $\begin{array}{l}\text { Relegado } \\
\text { Administrativo }\end{array}$ \\
\hline $\begin{array}{l}\text { MERCADO } \\
\text { OLIVA }\end{array}$ & SARA CELINDA & $\begin{array}{l}\text { Estudiante } \\
\text { Universitaria }\end{array}$ & Antofagasta & 01.06 .1975 & $\begin{array}{l}\text { Valdivia } \\
\left(14^{\mathrm{a}} \mathrm{R}\right)\end{array}$ & 00.01 .1976 & $\begin{array}{l}\text { Relegado por } \\
\text { Condena }\end{array}$ \\
\hline JIRÓN VARGAS & $\begin{array}{l}\text { SERGIO } \\
\text { ENRIQUE }\end{array}$ & $\begin{array}{l}\text { Estudiante } \\
\text { Universit. }\end{array}$ & Copiapó & 18.10 .1973 & $\begin{array}{l}\text { Porvenir } \\
\left(12^{\mathrm{a}} \mathrm{R}\right)\end{array}$ & 14.01 .1975 & $\begin{array}{l}\text { Relegado por } \\
\text { Condena }\end{array}$ \\
\hline $\begin{array}{l}\text { GONZÁLEZ } \\
\text { YAÑEZ }\end{array}$ & $\begin{array}{l}\text { GUILLERMO } \\
\text { ARTEMIO }\end{array}$ & $\begin{array}{l}\text { Vendedor de } \\
\text { Libros }\end{array}$ & Concepción & 15.10 .1975 & $\begin{array}{l}\text { Coyhaique } \\
\left(1^{\mathrm{a} R}\right)\end{array}$ & 18.11.1976 & $\begin{array}{l}\text { Relegado por } \\
\text { Condena }\end{array}$ \\
\hline
\end{tabular}

Fuente. Extracto de una tabla elaborada por FASIC

En esta tabla podemos observar en primera instancia las actividades a las que se dedicaban los detenidos antes de ser relegados. Logramos evidenciar entonces, que esta medida como ya lo enunciamos, no sólo afectó a la cúpula importante de la UP. Existiendo relegaciones el mismo mes del golpe, de estudiantes universitarios, comerciantes, entre otros. Efectuándose en su mayoría por Consejos de Guerra. Sin embargo, Raúl Mendoza fue relegado de forma administrativa bajo el antiguo decreto ley de relegación que

${ }^{41}$ Por repartir panfletos por el "no" condenan a estudiantes de Valparaíso. Revista Solidaridad, primera quincena de abril de 1978, p. 8. 
González Alarcón. Medidas, estrategias y etapas de la relegación durante la dictadura de Pinochet como mecanismo...

posteriormente fue modificado en 1980. Estas relegaciones administrativas se dieron en menor grado. Pero nos da cuenta de que ambas -judiciales y administrativas- se efectuaron de forma paralela, primando una sobre otra. Lo mismo ocurrirá en la década de los ochenta. Si bien la medida que prima es administrativa bajo el D.L. 3.168, también es posible encontrar relegaciones judiciales con penas de hasta 541 días.

Las detenciones en comisarías, cuarteles de la DINA u otras organizaciones podían durar bastante tiempo antes de que se sentenciara al inculpado con alguna de las medidas de represión. El estudiante universitario Sergio Jirón por ejemplo, había sido detenido el 18 de octubre de 1973 en la ciudad de Copiapó, pero no fue relegado hasta el 14 de enero de 1975. Estuvo detenido cerca de un año y medio. Muchas veces eran trasladados de un cuartel a otro, aplicando apremios físicos. De esta forma, constatamos que el castigo desde el momento de las detenciones hasta el término de las relegaciones se constituyó en una medida, si bien poco utilizada en esta etapa, pero muy cruda para quienes la sufrieron.

El malestar de lo ocurrido no sólo afectaba a los condenados, sino también a sus familias, quienes intentaban hacer todo lo posible por impedir las condenas a través de la interposición de constantes recursos de amparo. Bajo estos lineamientos surgió la creación de la Agrupación de Familiares de Relegados y Ex relegados (AFAREL) ${ }^{42}$, quienes ayudaban a los afectados.

A medida que pasaba el tiempo, el malestar crecía, las manifestaciones callejeras eran recurrentes. A tres años de impuesta la relegación administrativa y aceptada en la constitución de 1980, los relegados fueron aumentando exponencialmente en el transcurso de los años, y como ya se dio a entender anteriormente, este sistema fue aplicado en fechas íconos e importantes para la población en general. Cada vez se fueron conociendo casos nuevos de personas afectadas. Así se pudo ir entendiendo de mejor manera como era la situación de un relegado.

Un grupo de relegados por ejemplo, que fueron derivados a Pisagua, tuvieron que organizarse para pedir ayuda a la FASIC con la intención de que esta les pudiese facilitar los materiales pertinentes para un proyecto de trabajo que les ayudase a solventar sus necesidades básicas durante los tres meses de relegación. Este proyecto consistía en la formación de Talleres de Artesanía que les permitiera crear una fuente de ingresos para paliar en parte las necesidades materiales que tenían. El producto por su parte, seria vendido a través de la Vicaria de la Solidaridad y se constituiría como una permanente fuente de denuncias de los atropellos a los Derechos Humanos, ya que serían expuestos tanto dentro del país como en el exterior ${ }^{43}$.

\footnotetext{
${ }^{42}$ Para mayor información sobre la Agrupación de Familiares de Relegados y Exrelegados, visitar los archivos de la FASIC, los cuales se encuentran digitales en el siguiente link: http://www.fasic.cl. Destacamos la carta enviada por esta agrupación al Secretario Ejecutivo de FASIC, el señor Claudio González, el 30 de junio de 1986 donde se mencionan las tareas y el desarrollo que esta agrupación tuvo.

${ }^{43}$ Documento extraído de la FASIC, carta firmada por Javier Sáez, presidente de la Comisión Ejecutiva de Relegados de Pisagua, con fecha 5 de abril de 1980.
} 
En definitiva, la imposición del Decreto Ley de relegación administrativa en palabras de María Graciela Acuña:

"Se relaciona con la rearticulación de diferentes actores sociales, como los sindicatos, el movimiento estudiantil, los grupos de mujeres y de pobladores. En este contexto socio político de los ochenta en el cual las masas sociales se reactivaron y enfrentaron la dictadura, se produjeron las diferentes jornadas de protesta como también los paros nacionales. Estas eran una manifestación contra la precariedad y la cesantía que pasaban miles de trabajadores, [...]" (Acuña, 2015: 17).

En esta década la población comenzaba a perder el miedo y en consecuencia, se alzaba en contra de la dictadura de una forma más concreta de cómo se había estado desarrollando en años anteriores. Algunos artículos publicados en la naciente Revista Cauce daban cuenta de esto. En su segundo número de diciembre de 1983, aparecieron los siguientes titulares "Tortura, todos somos culpables", "1973 - 1983, Bitácora de la tortura" y "El miedo, como instrumento de dominio: el día que los chilenos comenzaron a perder el miedo" todos aludiendo a un repudio hacía los actos que realizaba la dictadura.

\section{Consideraciones finales}

Los objetivos que mantuvieron los mecanismos represivos durante la dictadura cívico-militar, estuvieron enfocados: en primer lugar, controlar a la sociedad, ya sea exiliando, relegando y asesinando a personas, y a su vez enviando un mensaje a la población de que si actuaban de tal forma, se sancionaría con las medidas ya señaladas; y en segundo término, rehabilitar, normalizar y disciplinar a quienes fueron sentenciados como opositores a las políticas del régimen. De esta manera, al situar la relegación como mecanismo de control social, buscamos señalar que ésta operó en la práctica, no sólo como una forma de castigo y sanción, sino también como una forma de corregir y enderezar las conductas de aquellos sujetos que en opinión de las autoridades de la época, sólo buscaban transgredir o alterar el orden interno. En otras palabras, la pena de relegación por un periodo determinado de tiempo, pretendía que el relegado modelara su conducta, aprendiera de la sanción y una vez terminada la pena, se reintegrara a la sociedad siendo obediente y funcional a los intereses que decretaba la dictadura.

Ahora bien, en las casi dos décadas de dictadura, los castigos fueron recurrentes, el cuerpo de los detenidos estaba en un sistema de coacción y de privación, de prohibiciones y de obligaciones. Muchos de los detenidos se encontraban mal física y sicológicamente, y con una mala atención médica. En las relegaciones no sólo importaba el sufrimiento físico, ni el dolor del cuerpo mismo, sino un sufrimiento sicológico, donde se fragmentaban los proyectos educativos, en el caso de los estudiantes; los trabajadores quedaban cesantes, no pudiendo aportar económicamente a su núcleo familiar. Del mismo modo en que la prisión quita la libertad a los delincuentes, la relegación privó al 
afectado de muchas facultades, los limitó a ejecutar los actos que se les daba autorización, manifestando que estos eran más peligrosos que los mismos criminales.

Sin embargo, los mecanismos de castigo dentro de la relegación fueron distintos a los de los campos de concentración, aquí la tortura se encontró en menor grado, se utilizó el castigo sicológico como dispositivo de control social, el cuerpo ya no era el objeto de la penalidad y puesto que ya no es este, son las subjetividades, un castigo que cause profundidad en el pensamiento.

\section{Referencias bibliográficas}

Fuentes

Archivos

Archivos de la Fundación de Ayuda Social de las Iglesias Cristianas (FASIC) en www. fasic.cl

Decreto Ley N¹2, "Cancelación personalidad jurídica de la CUT". 17 de septiembre de 1973.

Informe de la Comisión Nacional Sobre Prisión y Tortura, Santiago de Chile, 2004.

Informe de la Comisión Nacional de Verdad y Reconciliación, Santiago de Chile, 2007.

Revistas

Revista Chile-América, 1974.

Revista Ercilla, 1973.

Revista Solidaridad, 1976-1986.

Revista Hoy, 1978-1980.

Revista Cauce, 1983-1986.

Entrevistas

Juan Polizzi Contreras, viernes 16 de junio de 2017.

Sitios web

www.leychile.cl

www.memoriaviva.cl

Audiovisuales

Larraín, R. (Director), y Sanchex, M., y Soler, D. (Productores). (1991). La

Frontera. [Película]. Chile: Cine XXI y Ion Films.

Littín, M. (Director y productor). (2009). Dawson. Isla 10. [Película]. Chile: Azul

Films. 


\section{Bibliografía edita}

Acuña, M. G. (2015). La relegación como exilio interno. Santiago de Chile: FASIC.

Águila, G. (2012). La Historia Reciente en la Argentina: un balance. Revista Historiografias, $\mathrm{n}^{\circ} 3$, pp. 62-76.

Amunátegui, M. y Amunátegui, V. (1851). La reconquista española, apuntes para la historia de Chile 1814-1817. Santiago de Chile: Imprenta chilena.

Aylwin, A. (1990). 8 días de un relegado. Ediciones Arcoíris, Santiago de Chile;

Barros Arana, D. (1889). Historia general de chile, tomo X. Santiago de Chile: Imprenta cervantes.

Barros, R. (2005). La junta militar, Pinochet y la Constitución de 1980. Santiago de Chile: Editorial Sudamericana.

Béjar, H. (1991). La sociología de Norbert Elías: Las cadenas del miedo. Revista Española de Investigaciones Sociológicas (REIS), n56, pp. 61-82.

Bitar, S. (1990). Isla 10. Santiago de Chile: Pehuén.

Bonnefoy, P. (2005). Terrorismo de Estadio: prisioneros de guerra en un campo de deportes. Santiago de Chile: Ediciones Chile América-CESOC.

Bourdieu, P. (1999). Meditaciones pascalianas. Barcelona, España: Anagrama S.A.

Bourdieu, P. (2000). La dominación masculina. Barcelona, España: Anagrama S.A.

Bourdieu, P., y Wacquant, L. (1995). Respuestas, por una antropología reflexiva. México: Editorial Grijalbo.

Bresciano, J. A. (2010). El tiempo presente como campo historiográfico, ensayos teóricos y estudios de casos. Uruguay: Ediciones Cruz del Sur.

Brunner, J. (1980). Ideología, legitimación y disciplinamiento en la sociedad autoritaria. Santiago de Chile: FLACSO.

Campero, G. (1987). Entre la sobrevivencia y la acción política: Las organizaciones de pobladores en Santiago. Santiago de Chile: Ediciones ILET.

Cavallo, A., Salazar, M., y Sepúlveda, O. (2013). La historia oculta del régimen militar. Santiago de Chile: UQBAR.

Cavallo, A., y Serrano, M. (2013). Golpe, 11 de septiembre de 1973: Las 24 horas más dramáticas del siglo 20. Santiago de Chile: UQBAR.

Del Pozo, J. (2006). Exiliados, emigrados y retornados. Chilenos en América y Europa, 1973-2004. Santiago de Chile: RIL Editores.

Díaz, E. (2014). Relegación administrativa en Chile en el periodo 1980-1985. Tesis para obtener el título de Licenciatura en Historia, mención Estudios Culturales, UAHC; Santiago de Chile.

Ehijo, O., y Seelmann, G. (2003). Te recordamos, Quiriquina. Santiago de Chile: CESOC.

Flier, P. (2014). Dilemas, apuestas y reflexiones teórico-metodológicas para los abordajes en Historia Reciente. Argentina: Edup.

Foucault, M. (1976). Vigilar y castigar: nacimiento de la prisión. Buenos Aires: Siglo XXI.

Foucault, M. (1979). Microfisica del poder. Madrid: Edissa. 
González Alarcón. Medidas, estrategias y etapas de la relegación durante la dictadura de Pinochet como mecanismo...

Foucault, M. (2000). Los Anormales: Curso en el Collège de France (1974-1975). Buenos Aires: Fondo de Cultura Económica.

Franco, M., y Levín, F. (2007). Historia reciente. Perspectiva y desafíos para un campo en construcción. Buenos Aires: Paidós

Garcés, M., y de la Maza, G. (1985). La explosión de las mayorías. Protesta nacional 1983-1984. Santiago: ECO.

Garcés, M., y Leiva, S. (2005). El Golpe en La Legua. Los caminos de la historia y la memoria. Santiago de Chile: LOM Ediciones.

Garretón, M., Garretón, R., y Garretón, C. (1998). Por la fuerza sin la razón, análisis y textos de los bandos de la dictadura militar. Santiago de Chile: LOM Ediciones.

González, J. (2018). La relegación como exilio interno durante la dictadura cívicomilitar. El caso de la región del Bío-Bío, (1973-1986). Tesis para obtener el grado de Magíster en Historia, Universidad de Concepción.

Guillaudat, P., y Mouterde, P. (1998). Los movimientos sociales en Chile 1973-1993. Santiago de Chile: LOM Ediciones.

Horton, P., y Hunt, Ch. (1998). Sociología. México: McGraw-Hill.

Huneeus, C. (2000). El régimen de Pinochet. Santiago de Chile: sudamericana.

Ibáñez, W. (2013). El trinar de un gorrión: Campamento Militar de "Conchi” año 1978. Antofagasta, Chile: EMELNOR Impresores.

Iglesias, M. (2011). Rompiendo el cerco. El movimiento de pobladores contra la Dictadura. Santiago de Chile: Ediciones Radio Universidad de Chile.

Lechner, N. (2006). Obras escogidas. Tomo 1. Santiago de Chile: LOM Ediciones.

López, M., Figueroa, C., y Rajland, B. (2010). Temas y procesos de la historia reciente de América Latina. Santiago de Chile: Editorial Arcis.

Loveman, B., y Lira, E. (2000) Las ardientes cenizas del olvido: Vía chilena de reconciliación política 1932-1994, Santiago de Chile: LOM Ediciones.

Lúnecke, G. (2000). Violencia política (Violencia politica en Chile. 1983-1986). Santiago de Chile: Arzobispado de Santiago fundación documentación y archivo.

Marín, F., y Ravanal, L. (2013). Allende: "yo no me rendiré”. La investigación histórica y forense que descarta el suicidio. Santiago de Chile: CEIBO.

Melossi, D. (1985). El estado del control social. Conceptos sociológicos. México: Siglo XXI.

Monsálvez, D. (2012). La dictadura cívico-militar del general Augusto Pinochet como proceso institucionalizado de violencia política. Revista Sociedad Hoy, n²3, pp. 35-36.

Monsálvez, D. (2011). El miedo como problema político. Revista Tiempo y Espacio, $\mathrm{n}^{\circ} 26,121-130$.

Moulian, T. (2009). Contradicciones del desarrollo político chileno, 1920-1990. Santiago: LOM Ediciones.

Moulian, T. (1997). Chile actual, anatomía de un mito. Santiago de Chile: LOM Ediciones.

Oliver Olmo, P. (2005). El concepto de control social en la historia social: estructuración del orden y respuestas al desorden. Revista Historia Social, n51, pp. 73-91. 
Portales, F. (2010). Los mitos de la democracia chilena. Volumen 1. Desde la conquista hasta 1925. Santiago de Chile: Catalonia.

Rebolledo, J. (2012). La danza de los cuervos. El destino final de los detenidos desaparecidos. Santiago de Chile: CEIBO Ediciones.

Rebolledo, L. (2006). Memorias del desarraigo. Testimonios de exilio y retorno de hombres y mujeres de Chile. Santiago de Chile: Catalonia.

Rojas, J. (1993). La dictadura de Ibáñez y los sindicatos (1927-1931), Santiago de Chile: Editorial Universitaria S.A.

Salazar, G. (2006). La violencia político popular en las "Grandes Alamedas", la violencia en Chile 1947-1987 (una perspectiva histórica popular. Santiago de Chile: LOM Ediciones.

Salazar, G. (2013). Villa Grimaldi (Cuartel Terranova) volumen I: Historia, testimonio, reflexión. Santiago de Chile: LOM Ediciones.

Salazar, M. (2011). Las letras del horror, Tomo I: La DINA. Santiago de Chile: LOM Ediciones.

Salazar, M. (2012). Las letras del horror, tomo II: La CNI. Santiago de Chile: LOM Ediciones.

Soto, O. (1998). El último día de Salvador Allende: Crónica del asalto al Palacio de La Moneda contada por sus protagonistas. Madrid: Ediciones El País.

Teitelboim, V. (2002). Pisagua: La semilla en la arena. Santiago de Chile: LOM Ediciones.

Timmermann, F. (2015). El gran terror: Miedo, emoción y discurso. Chile, 1973-1980. Santiago de Chile: Ediciones Copygraph.

Valdivia, V., Álvarez, R., y Pinto, J. (2008). Su revolución contra nuestra revolución. Vol. II: La pugna marxista-gremialista en los ochenta. Santiago de Chile: LOM Ediciones.

Vega, M. E. (1999). No hay dolor inútil: La iglesia de Concepción y su defensa de los derechos humanos en la Región del Biobio entre 1973 y 1991. Concepción, Chile.

Vega, M. E. (2017). Nuestros días en el Estadio: Septiembre 1973 - Enero 1974. Concepción, Chile: Trama Impresores S.A.

Verdugo, P. (2008). Allende, como la casa blanca provocó su muerte. Santiago de Chile: Catalonia.

Weber, M. (2005). Economía y sociedad. México: Fondo de Cultura Económica.

Weinstein, J. (1989). Los jóvenes pobladores en las protestas nacionales (1983-1984). Santiago de Chile: CIDE.

Witker, A. (1975). Prisión en Chile. México: Fondo de Cultura Económica. 
